\title{
Luces fantasmas: palabra e imagen (Maborosi) ${ }^{1}$
}

\section{Phantom Lights: Word and Image (Maborosi)}

\author{
LINDA C. EHRLICH \\ Case Western Reserve University \\ Linda.ehrlich@gmail.com
}

Resumen: En su primer largometraje Maborosi, el laureado director Koreeda Hirokazu (nacido en 1962) logra hacer una refinada "danza" con la singular novela corta Maborosi no hikari (Luces fantasmas) de Miyamoto Teru, publicada en 1979 por Shinchō publishers, y posteriormente traducida al inglés por Roger $\mathrm{K}$. Thomas (en la colección Phantom Lights and Other Stories, Kurodahan Press, 2011). La intimidad de la narración de la protagonista en la novela y el poder evocativo de la puesta en escena de Kore-eda se complementan hasta parecer mutuos reflejos.

Palabras clave: adaptación cinematográfica, Miyamoto Teru, Kore-eda Hirozaku, Maborosi no hikari.

\begin{abstract}
In his first feature film, award-winning director Kore-eda Hirokazu (b. 1962) performs an elaborate "dance" with the original short story/ novella Maborosi no hikari (Phantom Lights) by Miya-moto Teru, first published in 1979 by Shinchō publishers and in English translation by Roger K. Thomas (as Phantom Lights and Other Stories, Kurodahan Press, 2011). The intimacy with which the protagonist narrates in the novel and the evocative power of Kore-eda's mise-en-scène comple-ment each other so that they seem mutual reflections.
\end{abstract}

Key Words: film adaptation, Miyamoto Teru, Kore-eda Hirozaju, Maborosi no hikari.

\footnotetext{
${ }^{1}$ La traducción del artículo, redactado originalmente en inglés, ha sido efectuada por Luis Melodelgado y Antonio Míguez.

Trasvases entre la literatura y el cine, I, 2019, págs. 37-50. 


\section{UN APUNTE SOBRE LA ADAPTACIÓN}

La adaptación cinematográfica que Kore-eda hace del texto de Miyamoto Teru ${ }^{2}$ puede ser vista como una «equivalencia» del original, de atenernos al término acunado por André Bazin (2000: 20), quien, escribiendo sobre la novela de Malraux y su posterior adaptación cinematográfica Man's Hope (Sierra de Teruel, 1939), afirma que «la fidelidad a una forma, bien sea literaria o no, es ilusoria: lo que importa es que exista equivalencia con lo que la forma quiere decir» (2000: 20). La versión cinematográfica de Maborosi no es un ejercicio de (la trillada) «fidelidad», pero tampoco constituye una desviación radical. Tanto el texto literario como la película se complementan, manteniendo cada uno su excepcional visión artística. Lo que Kore-eda aporta, en palabras del estudioso del cine James Naremore, son «códigos cinematográficos específicos» que transmutan el poderoso texto de Miyamoto, convirtiéndolo en una «meditación visual» (2000: 3) $)^{3}$. En esencia, Kore-eda ha logrado realizar un ejercicio de caméra stylo, por usar el término del crítico francés y cineasta Alexandre Astruc (1923-2016), quien afirmó que «el cine eventualmente habrá de soltarse de las demandas concretas e inmediatas de la narrativa, para convertirse en un medio de escritura tan flexible y sutil como lo es el lenguaje escrito» ${ }^{4}$.

Los argumentos en pro de la «fidelidad» (en la adaptación) tienden a favorecer la perspectiva del trasvase literal de «página a pantalla», y evidencian «un prejuicio cultural contra lo audiovisual» (MacCabe et al., 2011, s. pág.). En sus Concepts in Film Theory, Dudley Andrew escribe sobre tres posibles estrategias para la adaptación cinematográfica: el préstamo (uso general de los materiales y la forma del texto original), la intersección (cuando el texto original pasa intencional y relativamente intacto a la pantalla) y la transformación (la reproducción en la película de elementos esenciales del texto original) (Naremore, 2000: 19).

La adaptación cinematográfica de Kore-eda de la novela de Miyamoto corresponde sin duda a la tercera de las anteriores posibilidades, la

\footnotetext{
${ }^{2}$ Los nombres japoneses se mostrarán de la manera tradicional, adelantando el apellido.

${ }^{3}$ El crítico Stanley Kauffmann se refiere al estilo con el que Kore-eda filma Maborosi como «visual arias» (1996).

${ }^{4}$ El texto de Astrud, «Du Stylo à la caméra et de la caméra au stylo», fue publicado originalmente en L'Écran française (30/03/1948) y también está disponible en Peter Graham (ed.), The New Wave, Garden City, Doubleday, 1968, págs. 17-24 [en línea: http://www.newwavefilm.com/about/camera-stylo-astruc.shtml]. En palabras de Astruc, la idea de la caméra-stylo no es ni una escuela ni un movimiento artístico; se refiere a ella como una «tendencia» o una «nueva conciencia» en la que el director o guionista «escribe» con su cámara como lo hacen los novelistas con sus plumas.
} 
transformación. También concuerda con el pronunciamiento del teórico del cine Robert Stam: «El texto literario no es una estructura cerrada, sino abierta» (2000: 57).

En su prefacio a la traducción al inglés de Maborosi no hikari, la destacada traductora Juliet Winters Carpenter escribe sobre «el estilo tranquilo, etéreo y conmovedor de la prosa de Miyamoto» (2011: VIII). Es este tenor lo que es reproducido en la película. Leer la novela, y luego ver la película, equivale a aventurarse en una experiencia enriquecedora, llena de revelaciones sobre las profundidades del corazón humano. Las evocadoras imágenes de Kore-eda, su ritmo pausado (y con escasos diálogos), se complementan con el monólogo espiralado de Yumiko, en la versión original de Miyamoto. Hasta parecen mutuos reflejos.

\section{SINOPSIS DE LA NOVELA Y LA PELÍ́CULA}

En Maborosi, la protagonista Yumiko (Esumi Makiko) sufre una serie de pérdidas graves, la primera de ellas a la edad de doce años cuando su senil abuela decide súbitamente viajar a la aldea de su infancia en Shikoku, donde la abuela quisiera morir. Yumiko no logra convencerla de regresar al apartamento en Amagasaki (entre ōsaka y Kōbe), donde vive la familia. La abuela es de la ciudad de Sukumo, en la prefectura de Kōchi, en la isla de Shikoku. Hablamos de la tercera isla más grande del archipiélago japonés, con menos aglomeración urbana que el área de Osaka, donde vive la abuela con su hijo mayor en «una casa oscura como un túnel». Su senilidad no le permite entender cómo viajar de regreso a Shikoku, pero su deseo de regresar se impone. Esta es solo la primera de una serie de apariciones y desapariciones que afectan a Yumiko profundamente. La abuela se va para jamás volver.

Más adelante, el joven marido de Yumiko, Ikuo, inexplicablemente se suicida dejando abandonados en su pequeño apartamento en Amagasaki una cartera, su bici (robada), a su hijo de tres meses Yūichi y a Yumiko, a quien deja con la vida resquebrajada.

Pasan cinco años. El hijo de Yumiko ha crecido. Un matrimonio concertado con Tamio, quien también es viudo y quien tiene una hija pequeña, lleva a Yumiko a la remota aldea de Sosogi, en la costa del mar del Japón. Al principio, a ella, esta región del noroeste japonés le parece completamente desconocida. Es como si no estuviera en su propio país. El agreste entorno costero permite que parte de la densa tristeza de Yumiko comience a salir a la superficie y se disipe, pero una corta visita a Amagasaki para asistir a la boda de su hermano, la sumerge otra vez en el paisaje íntimo de su desesperación. A Yumiko la obsesiona la idea de no poder evitar que sus seres queridos desaparezcan para siempre. 


\section{El AUTOR: MiYAmoto Teru}

El autor de Maborosi no hikari, el novelista japonés Miyamoto Teru (nombre de pila, Miyamoto Masahito), nació en Kobe en 1941. El relato se desarrolla a finales de los años 70, que es justamente cuando el autor escribe la historia (en la película la época no queda claramente establecida). El propio Miyamoto creció en una familia que vivió momentos difíciles y que se mudaba constantemente (a Toyama, Amagasaki y otros lugares). Los negocios fallidos de su padre y el intento de suicidio de su deprimida madre afectaron enormemente al escritor. Desde joven, Miyamoto comenzó a leer obras literarias de forma voraz para escapar de la sombría situación económica de su familia, y también de los malestares mentales. Sus principales influencias como escritor incluyen a Joseph Conrad, al novelista japonés Shimazaki Tōson y a Baudelaire. Miyamoto no perteneció a ningún círculo literario (bundan), y se opuso abiertamente a la literatura de tendencia ideológica, que él catalogaba como kannen ('concepto abstracto') (Thomas, 2011: XIV).

En 1978, Miyamoto ganó el prestigioso premio Akutagawa de literatura por Hotarugawa (El río de las luciérnagas). Otras obras de Miyamoto adaptadas al cine fueron Dotonbori River, dirigida por Fukasaku Kinji (1982), y El río de las luciérnagas, dirigida por Sugawa Eizō (1987). Miyamoto ganó el premio Dazai Osamu Prize por Doro no kawa (Muddy River) en 1977. Esta historia fue llevada al cine en 1981, dirigida por Oguri Kōhei, y fue galardonada.

Miyamoto escribió la novela Maboroshi no hikari cuando tenía treinta y un años. Lo hizo inspirado por la fotografía de una anciana, situada de espaldas a la cámara frente al poderoso mar invernal de Noto.

\section{El Director: Kore-EDA HirokaZU}

Kore-eda Hirokazu nació en Tokio en 1962. El director se vio afectado por la creciente senilidad de su abuelo (cuando Kore-eda tenía aproximadamente seis años). Temas como el de la memoria y el dolor de la pérdida son evidentes en sus películas. Kore-eda, quien no asistió a una academia de cinematografía, ha declarado que su escuela fue el «ensayo y error». Pensó dedicarse a escribir novelas (y, de hecho, ha compuesto novelas que acompañan a algunos de sus propios guiones cinematográficos). Kore-eda se unió a la TV Man Union en 1987. Esta sui generis empresa, fundada en 1970, fue la primera compañía de televisión independiente de Japón. En 2014, Kore-eda lanzó su propia compañía productora, Bun-Buku, una cooperativa de producciones en sociedad con otros dos directores de 
importancia, Nishikawa Miwa y Sunada Mami ${ }^{5}$. El verdadero deseo de Koreeda fue el de crear una compañía dedicada únicamente a la producción de películas.

En 1995, Kore-eda fue el primer ganador de una beca ofrecida por la Asociación Internacional de Cine de Tokio para directores noveles con una prometedora proyección. ¡No está mal para una persona que nunca acudió a una escuela de cine! Su primer largometraje, Maborosi, recibió galardones en el Festival de Cine de Venecia y en el Festival Internacional de cine de Vancouver. Además, en 1995, recibió el Golden Hugo en el Festival Internacional de Cine de Chicago. Su segunda película, After Life (Wandarufuru raifu, 1998), ganó el gran premio del Festival de Nantes y el premio a la mejor película y al mejor guion cinematográfico en el Festival de Cine de Buenos Aires. El actor Yagira Yūya, de Nadie Sabe (Daremo shiranai, 2004), recibió el premio al mejor actor en la $57^{\mathrm{a}}$ edición del Festival de Cannes, siendo la persona más joven en la historia del premio en recibirlo. De tal padre, tal hijo (Soshite chichi ni naru, 2013) ganó el premio del jurado de Cannes. El más reciente filme de Kore-eda, Un asunto de familia (Manbiki Kazoku, 2018), ganó la Palma de Oro en el Festival de Cannes y fue nominada en la categoría de mejor película en lengua extranjera de los premios Óscar. Esta es solo una pequeña lista de sus logros de primer nivel. La importancia de las películas de Kore-eda va más allá de los premios en competiciones internacionales; recientemente el director fue galardonado con el premio Donostia en la $66^{a}$ edición del Festival de San Sebastián (2018). Es el primer asiático en recibir esta distinción ${ }^{6}$.

\section{ESTRUCTURA NARRATIVA}

La novela está estructurada como el continuo diálogo de Yumiko con su fallecido esposo, Ikuo. La conmovedora historia de Miyamoto Teru pudo haber sido adaptada para la gran pantalla de múltiples formas. Una posibilidad hubiera sido la de utilizar un narrador en primera persona y proceder con un flashback extendido, como sucede en la famosa película Matar a un ruiseñor (1962). Otra posibilidad pudo haber sido el empleo de un narrador omnisciente, quien complementa lo que no vemos en la pantalla. Kore-eda eligió una tercera posibilidad: nos dio a sus espectadores

\footnotetext{
5 «Kore-eda Hirokazu kantoku aete kaisha miman no kaisha o mezasu' -originaru no eiga sakuhin o umidashitsuzukeru soshikizukuri to wa» (Hori Kaoru, Think About, 07/12/2017).

${ }^{6}$ El premio Donostia reconoce a grandes personalidades del cine (el primer galardonado fue Gregory Peck). Agnès Varda y Francis Ford Coppola son otros dos directores que han recibido este honor.
} 
un acceso inusual a cuanto sucede en la mente de Yumiko mientras, paradójicamente, nos mantiene visualmente a cierta distancia de ella.

Las palabras que Miyamoto usa en los monólogos y en los diálogos de su historia, nos dan a conocer el lugar donde todo acontece, más de lo que aprendemos al escuchar los breves diálogos, o de lo que leemos en los subtítulos de la película. En ambas, tanto en la novela como en la película, estamos inmersos en dos lugares, Amagasaki y Sosogi, y en los dos se habla un japonés no convencional. En la película, Tamio cambia frecuentemente de dialecto en las escenas del mar de Japón, y Yumiko termina por adquirir algunas expresiones locales de esa región costera.

En la novela de Miyamoto, los lectores tenemos mucho más acceso a la historia personal de Yumiko (esos detalles no aparecen en la película). De acuerdo con esta historia, tanto Yumiko como Ikuo no terminaron la secundaria por razones económicas y porque Ikuo decidió empezar a trabajar como aprendiz, y no porque él fuera un mal estudiante. En la novela vemos cómo la policía presionó al padre de Yumiko por la desaparición de la abuela, e incluso cavaron bajo el tatami de su apartamento para ver si ahí estaba oculto el cadáver. Todo esto sucedió en 1957, «un año lleno de acontecimientos siniestros en mi familia» (Miyamoto, 2011: 122). En sus reflexiones escritas, Yumiko recuerda: «Incluso después de rellenar el hueco, y reemplazar el tatami, y colocar la destartalada cajonera y la alacena donde estaban, el olor de la tierra parecía no querer desaparecer» (2011: 128). Los restos de la abuela nunca fueron encontrados. Por este hecho, ella escribe: «Estoy convencida de que nadie ha tenido una muerte más misteriosa» (2011: 129). Es aquí cuando Ikuo se le presenta a Yumiko por primera vez.

La siguiente desaparición extraña fue el suicidio de Ikuo. En la novela, Yumiko narra: «En lo profundo de mi aturdido corazón había otro corazón que no podía ni llorar ni gritar, que seguía hundiéndose en las profundidades más oscuras de la tierra» (2011: 121). En este momento, el director Koreeda hace que la abatida postura y la mirada perdida deYumiko transmitan la información sobre los que fueron los días posteriores a la repentina desaparición de Ikuo. En la novela, Yumiko dice en tono lastimero: «Eventualmente comencé a imaginar que a veces detendrías tu silenciosa marcha y volverías a verme» $(2011: 121)$.

Los detalles sobre cómo Yumiko sobrevive económicamente durante los cinco años posteriores a la muerte de Ikuo se explican en el texto escrito, pero no están incluidos en la película. Sabemos por las palabras de Miyamoto que ella empieza a trabajar en uno de los llamados love hotels en su barrio, limpiando habitaciones y trabajando como recepcionista: «En la calle debajo de nuestra ventana, había tres love hotels, uno junto al otro. El rojo y el azul de sus letreros de Neón se mezclaban para bañarlo todo en ese tono morado oscuro» (2011: 119). 
Aunque probablemente los espectadores japoneses no necesitarán esta explicación, es necesario decir que Kore-eda elimina cualquier mención de una visita anterior de Tamio, con su hija Tomoko, para encontrarse con Yumiko en Amagasaki (algo que sí se menciona en el diálogo del texto literario).

Cuando Yumiko comienza su viaje a Sosogi para vivir con su nuevo marido Tamio, a los lectores de la novela se nos presenta un personaje que no aparece en la película: una mujer coreana, la señora Kan, quien tiene tres hijos, y con quien Yumiko se encuentra por casualidad en la estación. Al comienzo del viaje, la mente de Yumiko es literalmente «un revoltijo de ansiedad, incertidumbre y arrepentimiento» (2011: 133). La señora Kan (a quien acaba de conocer) termina animando a Yumiko a continuar con su viaje hacia el norte hasta Sosogi. La novela también nos deja conocer más detalles sobre el largo viaje que hacen Yumiko y Yüichi, en varios trenes, para llegar a su nuevo hogar. En la novela Yumiko comenta: «hasta Wajima hablé contigo, un hombre muerto, mientras miraba por la ventana. Ni siquiera recuerdo lo que dije» (2011: 134).

Cuando llega a Sosogi, Yumiko ve grandes bandadas de «cuervos, gaviotas y gorriones, que se movían en el aire como si fueran humaredas... [Sosogi] parecía mucho más empobrecido de lo que había imaginado» (2011: 139). Kore-eda nos muestra esta desolación con una vista de la vacía estación de tren, con sus vías en mal estado. La novela también da a entender que los jóvenes, e incluso muchos de los maridos, han abandonado Sosogi por ir en busca de trabajo a otros lugares, dejando la ciudad para las mujeres y los ancianos. Dice Yumiko: «Me di cuenta lo triste que era no ver a hombres y mujeres jóvenes, no verlos en el mejor momento de sus vidas productivas» (2011: 139).

Tanto en la novela como en el filme, Yumiko regresa a Amagasaki para asistir a la boda de su hermano, visita con que revive parcialmente su profunda tristeza. Después de escuchar del propietario del kissaten ('café') que Ikuo se detuvo allí a conversar antes de suicidarse, ella reflexiona en su soliloquio: «Las dos horas transcurridas entre ese momento y tu caminar por entre las ferrovías, continuaron creciendo hasta volverse un vacío inmenso y amorfo» (2011: 146-147).

\section{LA ESCENA CATÁRTICA}

Aproximadamente a las dos terceras partes de la novela, Miyamoto introduce la historia inquietante de un hombre que sube al autobús en el que viaja Yumiko, mientras afuera cae una fuerte tormenta de nieve, escena que no aparece en la versión cinematográfica. El hombre, de unos treinta años y bizco (como lo era Ikuo a veces) toma el autobús, pero parece que lo mueve algo más que el interés de viajar. Este hombre «mantuvo su exhausta mirada 
sobre el mar» (Miyamoto, 2011: 141). Yumiko sintió que el individuo podría estar pensando en suicidarse: «Quizá debido a mi sentimentalismo, presentí algo fuera de lo común en él. Se me ocurrió que había venido aquí para morir» (2011: 141-42). Aunque no era su parada, ella siguió al hombre cuando él se bajó del autobús, pero al poco tiempo perdió su rastro en la nieve.

En este punto crucial de la historia, Yumiko se detiene junto a un barco de pesca a llorar: «En ese momento desperté a la realidad de tu muerte» (2011: 143). Afortunadamente, Tamio la encuentra allí después buscarla por todas partes. Como ocurre en la penúltima secuencia de la película, Yumiko estuvo cerca de morir congelada.

En la película, la escena catártica también acontece en el espacio liminal entre el mar y la tierra firme. La escena es filmada en un plano secuencia significativamente contenido (de dos minutos y dieciocho segundos) y con cámara fija.

Una Yumiko angustiada, de apariencia casi sobrenatural, sigue un cortejo fúnebre que atraviesa la campiña hasta detenerse junto a una pira funeraria, ubicada en una franja de tierra rodeada en tres partes por el mar. Allí, puede finalmente manifestar su angustia por el suicidio de su primer marido. Tamio llega y le habla de una luz fantasmal, un maborosi que puede engañar a una persona cuando menos se lo espera. En el monólogo de Yumiko en la novela, el concepto es expresado así: «Me he sorprendido a mí misma varias veces contemplando distraída esas lucecitas ondular apiñadas en las crestas de las ondas... son inquietantes, como si fueran vislumbres de un sueño» (2011: 114).

El inusual plano picado del cortejo fúnebre recuerda a la toma del tren deteniéndose en la estación de Noto, cuando Yumiko y Yūichi llegan por primera vez a su nuevo hogar. Cuando se filmaba esta penúltima secuencia, el viento oceánico arrojó nieve (sorpresivamente).

A los espectadores acostumbrados a los taquillazos estilo Hollywood podría sorprenderles negativamente la sobriedad de la importante escena. Kore-eda explica que «hice del plano secuencia la base de esta película [...], quise mostrar su tristeza y su dolor reverberando en los sonidos, las luces y las sombras del kukan ('espacio abierto/vacío'), como si en el espacio exterior pudiésemos ver reflejado el mundo emocional deYumiko» (Ehrlich y Kishi, 2003-4: 61-62).

Una vez terminadas las honras fúnebres, la pira continúa ardiendo. De pie, bajo el purpurino cielo y junto al oscurecido océano, Yumiko y Tamio parecen ser «tragados por los elementos» (Mizuta Lippit, 2005: 142). Lo que vemos entonces son pinceladas caligráficas en el horizonte. La música nos indica que los acontecimientos están llegando a su clímax. En esa franja de tierra cubierta por el humo del fuego, Yumiko y Tamio se encuentran en 
el umbral entre la vida y la muerte. Es como si estuviéramos observando un mugen Noh ('Noh sobrenatural'), cuando los espíritus adquieren forma corporal. Cuando Tamio habla con Yumiko lo hace tranquilamente, no hay abrazos, ellos no corren mutuamente a su encuentro, no hay un primer plano dramático. En este reino de la muerte tales acciones carecen de sentido. La música simplemente se disipa y los sonidos del mar terminan por imponerse.

Tras aceptar el misterio que encierran los maborosi, Yumiko se aleja de la hoguera y del mar, y sigue a Tamio, a la seguridad de la tierra firme. Al día siguiente, ella se sienta en el engawa ('porche') de su nueva casa, encarando la misma luz de siempre. En este final abierto de Maborosi, a los espectadores se nos pide encontrar las pequeñas pistas que nos alejan de la abrumadora escena nocturna junto al mar.

\section{CODA}

La novela también termina con un final abierto: «Ah [Ikuo], realmente sienta bien hablar así contigo. A veces, cuando comienzo a hablar, de alguna parte en mis adentros brota un dolor cálido, agradable» (Miyamoto, 2011: 155). Después ella pasa a comentar cómo, a veces, escucha «la tos flemosa» de su suegro, y recuerda que «ya casi es hora de que Yüichi vuelva de la escuela» (2011: 155).

En la novela, el monólogo inicial de Yumiko da vueltas en círculos: «La imagen tuya, encorvado, alejándote caminando junto a las ferrovías cuando ya ha dejado de llover, sin importar lo que haga para borrarla de mi mente, siempre aflora desde algún recoveco de mi consciencia» (2011: 114). Cuando comienza la novela Yumiko recuerda también las palabras de su suegro: «hay momentos en los que la luz baila... en la superficie del mar, pero solo una parte de las ondas se ilumina. Mi suegro me dijo que este efecto hace trucos con tu mente, si las has estado mirando desde lejos» (2011: 113).

Una diferencia importante entre la novela y la película, es que la primera nos cuenta con detalle lo que sucede después de que Yumiko finalmente se pregunta por aquello que la ha estado atormentando desde el suicidio de Ikuo: ¿por qué quiso morirse de esa forma? Los detalles que Miyamoto nos ofrece son cotidianos: Yumiko (ante la sugerencia de Tamio) convierte su casa en un exitoso hostal, durante la temporada turística, para ayudar a su nueva familia a sobrevivir económicamente (y también para estar ocupada). Los ingresos familiares son siempre escasos, a pesar del trabajo de Tamio como chef en un restaurante local. En otras palabras: Yumiko se convierte en la exitosa dueña de su propia empresa, y en este tono se ajusta al ritmo de su nueva vida. «Tamio y Tomoko han pasado a ser personas indispensables 
para mí», nos cuenta ella en la novela (2011: 153). Así, en cierta medida, el fantasma de Ikuo ha sido conjurado.

El comienzo de la novela queda reflejado en las secuencias finales de la película. Yumiko, como narradora, comenta: «Estoy sentada en la ventana de la planta de arriba, disfrutando del cálido sol primaveral, mirando la calma mar y el coche de mi marido cuando se va a trabajar» (2011: 114).

¿Hubieran ayudado los detalles adicionales proporcionados en la novela (del pasado o del futuro), para que los espectadores aprecien mejor la película? Particularmente tengo dudas. Como escribió el historiador de cine Donald Richie, «en Maborosi, Kore-eda no solamente rechaza los argumentos artificiosos o forzados, o enfatizar a través del montaje, sino también la locura consumista de las urbes japonesas... Notamos detalles y patrones... cada uno con sus cuidadosamente planeados ecos y repeticiones» (2001: 241).

El efecto general producido por cualquier película de Kore-eda es semejante a una superficie tranquila que esconde debajo de sí muchas capas. Algunas de esas capas son turbulentas. Muchas incluso nunca llegan a definirse por completo. Algunas otras, por el contrario, ofrecen destellos de esperanza. Su fascinación por la memoria es multisensorial y, sobre esto, el director dice: «pienso que la gente recuerda imágenes evocadas por sonidos, y recuerda sonidos evocados por imágenes» (Gerow y Tanaka, 1999: 9).

\section{CódigOS ESPECÍfICOS CINEMATOGRÁFICOS 8.1. Primer plano}

En una reseña realizada para el semanario neoyorquino The Nation, Stuart Klawans observa que «la acción dentro del encuadre es siempre exquisitamente naturalista, con los actores dando a cada gesto y a cada objeto el peso justo» (1996). En una forma metonímica, los objetos representan a la persona que los poseía, o a quien tenía relación con ellos ${ }^{7}$. El raro primer plano de una tetera en la comisaría y, junto a ella, el timbre de la bicicleta sobre la mesa, crean una especie de «bodegón de luto». Como apunta el investigador Tim Iles, este tipo de primeros planos «se centran en la ausencia de Ikuo» (2005: 214).

El álbum de fotos, como los videos de la siguiente película de Kore-eda, After Life, son verdaderos depósitos de recuerdos. Akogare ('añoranza') es lo

\footnotetext{
${ }^{7}$ Como observó Rey Chow en su ensayo sobre el uso del objeto cotidiano en los filmes de Zhang Yimou y Wong Kar-Wai, «en forma de utensilios rústicos, actividades y comportamientos, lo cotidiano se presenta de forma cinematográfica con las connotaciones del esfuerzo del ser humano, su persistencia y resistencia, y su poder redentor» (2002: 644).
} 
que emana de esos objetos: el anhelo imposible por volver a vivir el pasado. Aunque las suyas no son consideradas películas "románticas", Maborosi (así como su siguiente película, Air Doll/Küki ningyõ, de 2009) ofrece una reflexión profunda sobre el amor entre un hombre y una mujer. La ausencia de primeros planos de la cara de Yumiko no hace que disminuya nuestra comprensión de que la felicidad que ella siente junto a Ikuo solo es comparable con la profundidad de su pena.

Otro objeto revelador en Maborosi es aquella cosita verde y redonda que Yūichi opone a la luz: un trozo de amedama ('caramelo duro') que le dio el vecino (un señor mayor en Amagasaki) cuando Yumiko, su madre (Kiuchi Midori) y Yüichi salieron por última vez del edificio de apartamentos de Amagasaki. En la siguiente película de Kore-eda, Air Doll, el personaje de Nozomi acerca a la ventana un cristal de forma similar, haciendo que la luz lo atraviese como a un prisma. Estos coloridos objetos están llenos de promesa y de juventud, y constituyen un bienvenido contraste frente a la paleta sombría de algunas escenas.

En el libro Seeing like the Buddha, la especialista en budismo Francisca Cho nos recuerda que en el pensamiento budista, «el vacío existe, en forma paradójica, en la apariencia de las cosas. No es algo que pueda ser encontrado fuera de ellas» $(2017: 96)^{8}$. Aunque no estoy de acuerdo con su intento de ver Maborosi como «un paso hacia una cinematografía diferente a la japonesa y asiática», admiro lo que nos deja ver su análisis de la película sobre el uso de las sombras, y que nos recuerde un concepto propio de la estética japonesa, el yügen (un tipo de oscuridad que sugiere una profundidad de las cosas más allá de su explicación intelectual) (2017: 106, 93). En su análisis histórico del término yügen, Cho lo relaciona con el término chino yuxuan y con el Daodejing (atribuido a Laozi en el siglo VI BCE), y también con la doctrina del vacío y con el concepto mu ('el no ser') de varias escuelas budistas (2017: 156). La autora cita al historiador del arte Konishi Jin'ichi, quien señala que el «yügen ('un sentido de profundidad') emerge paradójicamente de una expresión incompleta» $(2017: 95)^{9}$. Esta «expresión incompleta» es sin duda lo que relaciona a Maborosi con el budismo, pero yo dejaría las cosas así, en lugar de anunciar que es una historia con valores universales y trascendentales.

\footnotetext{
${ }^{8}$ Además de un detallado análisis de los textos budistas más importantes, Cho habla de In Praise of Shadows (1933) de Tanizaki Junichirō y de la obra de Roland Barthes The Empire of Signs (1970), además del Film Noir desde los años 50 hasta Blade Runner. ${ }^{9}$ Cita las palabras de Konishi Jin'ichi en A History of Japanese Literature. III, trad. de A. Gatten y N. Teele, Princeton University Press, 1991, pág. 183.
} 
Inicialmente el autor Miyamoto Teru se mostró escéptico sobre la adaptación de su novela al cine. Quedó convencido tras hablar con el director Kore-eda Hirokazu y escuchar su promesa de que evitaría el sensacionalismo. De hecho, el productor Gozu Naoe dijo que Miyamoto vendió los derechos de autor por solo diez dólares (Milestone Film and Video press kit). Después de ver la película, Miyamoto la alabó con entusiasmo: «Adaptaron una historia que parecía no pertenecer a ningún lado, y lograron hacer que pertenezca a todas partes» (Producer's statement, Milestone Film and Video press kit).

\subsection{Luz}

Tanto Kore-eda como el director de fotografía Nakabori Masao mantienen la cámara alejada de los actores. Según el director, Maborosi «documenta las luces y las sombras que parpadean dentro de una mujer» (Director's Statement, Milestone Film and Video press kit). Es una película luminosa, filmada en exteriores y usando la luz natural. En este sentido, el director dijo que quería «mirar con atención cómo aparecen la forma humana y los colores bajo estas condiciones. Tenía la intención de escuchar los sonidos que emergían de la oscuridad» (Director's Statement, Milestone Film andVideo press kit).

En retrospectiva, Kore-eda se cuestiona el riguroso esquema estilístico que usó en Maborosi. Sobre esto, el director taiwanés Hou Hsiao-hsien le hizo la siguiente crítica: «En vez de decidir el estilo de la película de antemano, ¿no sería mejor que el estilo salga del encuentro natural entre los actores y el paisaje circundante?» (Ehrlich y Kishi, 2003-4: 43).

\subsection{Sonido}

Aunque los sonidos son sugeridos en el texto, el espectador de la película puede tener un encuentro directo con ellos, solo que ahora presentados con la dimensión propia de la cinematografía.

En las escenas de Sosogi, cuando Yumiko empieza a adaptarse a su nuevo entorno, Kore-eda añade un hermoso estribillo de la canción Akaihana shiroihana ('flor roja, flor blanca') que conecta un montaje con imágenes del mar, la aldea y escenas de espacios interiores. La canción contiene unas líneas muy emotivas que dicen: «Cortaré una flor roja y te la daré, mi amor, y la verás brillar como un sol en tu cabello. Cortaré una flor blanca y la veré brillar en su varonil pecho como si fuera la luna» ${ }^{10}$.

${ }^{10}$ Toques de rojo marcan esta película y señalan la posibilidad de que la deprimida Yumiko recupere su sentido de la vitalidad. El color rojo se usa cuidadosamente para indicar un nuevo foco: llamas rojas en la estufa debajo de la caldera en la oficina de la 
La banda sonora del compositor taiwanés Chen Ming-Chang (compositor de la película Dust in the Wind, del director Hou hsaio-hsien) mezcla motivos orquestales europeos con instrumentos tradicionales asiáticos.

A los espectadores nos son presentados el sonido del timbre de la bicicleta y el del rugido del tren desde el principio de la película, cuando aún no comprendemos lo que significan. Aun cuando la pantalla esté oscura, podremos escuchar en el timbre de la bici la nota insistente del amor de Yumiko hacia Ikuo.

\section{LA INTENCIÓN: DECLAR ACIONES DEL ESCRITOR Y DEL CINEASTA}

¿Son la novela o la película nihilistas? Kore-eda responde negativamente: «Uno puede reafirmar la vida cada vez que piensa en la muerte y en el dolor de una pérdida.Y uno puede repetir este proceso una y otra vez. Esto es algo que hacemos de forma activa. Por esta razón discrepo con quienes digan que el tema de esta película es el destino, que su mensaje es que debemos aceptar todo lo que se nos presente» (Milestone Film andVideo press kit). La declaración va en consonancia con el espíritu de la explicación de Miyamoto Teru: «Sentí el deseo de escribir sobre personas que intentan salir adelante, que luchan por vivir» (Miyamoto, 2011: XIV). Como escribe Bazin en su ensayo sobre la adaptación que en 1936 hizo Jean Renoir del relato corto de Maupassant «Une partie de campagne», en la colaboración entre Miyamoto y Kore-eda encontramos «la refracción de una obra en la conciencia de otro creador» (2000: 20).

La intimidad con la que narra Yumiko y el poder evocativo de la mise-enscène de Kore-eda, se complementan creando una historia que perdura como la estela de un barco. Lo uno funciona bien sin lo otro, pero juntos crean algo mágico, como si fueran luces bailando sobre la superficie del mar.

\section{BibliografíA CITADA}

BAzin, André (2000), «Adaptation, or the Cinema as Digest», en J. Naremore (ed.), Film Adaptation, New Brunswick, Rutgers University Press.

CHO, Francisca (2017), Seeing Like the Buddha: Enlightenment Through Film, New York, SUNY Press.

policía, rojo alrededor de las luces del tren, la canción sobre akai hana ('flor roja'), asientos rojos del tren de la montaña, de las mochilas de los niños, y así sucesivamente. 
CHOw, Rey (2002), «Sentimental Returns: On the Uses of the Everyday in the Recent Films of Zhang Yimou and Wong kar-wai», New Literary History, 33.

Ehrlich, Linda C. y Yoshiko KISHI (2003-04), «The Filmmaker as Listener: A New Look at Kore-eda», Cinemaya, 61-62.

Gerow, Aaron y Junko TANAKA (1999), «Documentarists of Japan \#12: Kore-eda Hirokazu», Documentary Box, 13.

ILES, Timothy (2005), «The Light of Life and Death. The Function of Cinematography and Lighting in Two Films by Kore-eda Hirokazu», Asian Cinema, 16/1.

KaufFmann, Stanley (1996), «Quest and Questing», The New Republic.

KLAwans, Stewart (1996), «Review of Maborosi», The Nation.

MACCABE, Colin et al. (eds.) (2011), True to the Spirit: Film Adaptation and the Question of Fidelity, New York, Oxford University Press.

Miyamoto, Teru (2011), Phantom Lights and Other Stories, pról. de J. Winters Carpenter y trad. de R. K. Thomas, Kumamoto, Kurodahan Press.

MizuTa LipPit, Akira (2005), Atomic Light (Shadow Optics), Minneapolis, University of Minnesota Press.

NAREMORE, Jmes (2000), «Introduction», en J. Naremore (ed.), Film Adaptation, New Brunswick, Rutgers University Press.

RichIE, Donald (2001), One Hundred Years of Japanese Film, Tokyo/New York, Kodansha.

STAM, Robert (2000), «Beyond Fidelity: The Dialogics of Adaptation», en J. Naremore (ed.), Film Adaptation, New Brunswick, Rutgers University Press.

Thomas, Roger K. (2011), «Introduction» a T. Miyamoto, Phantom Lights and Other Stories, Kumamoto, Kurodahan Press.

Fecha de recepción: 23/07/2019.

Fecha de aceptación: 29/07/2019. 